\title{
ELABORAÇÃO DE IOGURTE COM DIFERENTES CONCENTRAÇÕES DE SÓLIDOS TOTAIS, ANÁLISE FÍSICO-QUÍMICA E PERFIL DA TEXTURA
}

\section{ELABORATION OF YOGHURT WITH DIFFER ENT CONCENTRATIONS OF SOLIDS TOTAL, ANALYSIS, CHEMICAL-PHYSICAL AND TEXTURE OF PROFILE}

\author{
Daniel Mantovani ${ }^{1}$; Marcos Lúcio Corazza ${ }^{2}$; Lúcio Cardozo Filho ${ }^{3}$; Sílvio Claudio da Costa ${ }^{3}$ \\ ${ }^{1}$ Universidade Federal do Paraná - UFPR - Curitiba - Brasil danieluns @ yahoo.com \\ ${ }^{2}$ Universidade Federal do Paraná - UFPR - Curitiba - Brasil \\ ${ }^{3}$ Universidade Estadual de Maringá - UEM - Maringá - Brasil
}

\begin{abstract}
Resumo
O grande consumo de produtos lácteos tais como os iogurtes, que provêm de fontes de origem animal, disponibilizam aos consumidores deste alimento, fontes de minerais, aminoácidos, vitaminas entre outras fontes. E no Brasil, diversas pesquisas vêm propiciando o desenvolvimento de iogurtes que possuem uma consistência mais firme e atrativo ao paladar. Portanto, esse estudo objetivou desenvolver um produto lácteo fermentado com diferentes concentrações de sólidos totais e com sabor goiaba a fim de verificar e avaliar o perfil de textura e as modificações físico-químicas decorrentes da influência das diferentes concentrações de sólidos totais. As formulações foram preparadas utilizando duas formulações controle, uma com espessante $(E S P)$ e outra padrão $(P)$. $E$ demais formulações idênticas como: 5 e $10 \%$ de leite em pó (LP) e 5 e $10 \%$ de soro de leite (SP). Entre as análises físico-químicas estudadas, todos os valores obtidos durante os ensaios estiveram em conformidade com a legislação específica para iogurtes. E para o estudo voltado ao perfil da textura, os melhores resultados obtidos para os atributos estudados ficaram para o: $P$, ESP, LP $10 \%$ e SP 5\% que mantiveram características aceitáveis para a adesividade em iogurtes. $O$ atributo coesividade, apresentou valores considerados satisfatórios para esses tratamentos $e$ produto final. E ao relacionarmos o atributo gomosidade, o mesmo caracterizou-se como instável entre todos os tratamentos.
\end{abstract}

Palav ras-chave: sólidos totais, atributos da textura, desenvolvimento.

\section{Introdução}

O consumo de bebidas lácteas fermentadas é muito difundida a nível mundial, e seu enriquecimento ou fortificação implica na concentração de sólidos para obter propriedades reológicas desejadas para uma bebida láctea e iogurtes (ORDÓÑEZ, 2005). O iogurte é originário da Ásia, onde os turcos viviam como nômades e das regiões orientais do Balcãs, especialmente da Bulgária (SOROA, 1980; SÁ e BARBOSA, 1990). É um alimento de alto valor nutritivo, 
tradicionalmente consumido devido fundamentalmente a sua imagem de um produto saudável (EARLY, 2000). Além de nutritivo, trata-se de um alimento com as seguintes propriedades terapêuticas: redução das reações alérgicas à proteína, estímulo de secreções intestinais, facilitador da absorção de fósforo e cálcio, ajuda na síntese de vitamina $\mathrm{K}$ e vitaminas do complexo $\mathrm{B}$, redução do nível de colesterol quando usado leite desnatado (LIMA, 1975). E o consumo de iogurtes cresceu muito durante o último quarto deste século, em especial com a introdução do desenvolvimento de novos produtos, na adição de aromas de frutas, vindo a aumentar a sua aceitação (ÇON et al., 1996).

Em geral a produção de iogurte compreende as seguintes etapas: homogeneização, tratamento térmico, resfriamento, inoculação, incubação, refrigeração, quebra do gel, envase e armazenamento (FERREIRA, 2001; TAMINE et al., 1991).

Existem diversos tipos de iogurtes, entre eles o tradicional e o batido, sendo que o tradicional possui consistência mais firme (MIRANDA et al., 1999; ROCHA et al., 2003). O iogurte tradicional é incubado já na embalagem de venda para que não haja a quebra da coalhada.

E para manter a consistência do iogurte fabricado no Brasil, ocorre a adição do extrato seco de procedência láctea (ESL) com diferentes concentrações, um exemplo disso é o iogurte natural, de consistência firme onde seu enriquecimento pode chegar até 16 a $18 \%$ de ESL enquanto o iogurte batido requer viscosidade elevada, e somente se enriquece com até 13 a 14\%, além da permissão do uso de espessantes (ORDÓÑEZ, 2005).

De acordo com a legislação brasileira voltada a leites fermentados, resolução $\mathrm{n}^{0} 5$ de 13 de novembro de 2000 são incluídos os diferentes tipos de iogurte, classificados quanto ao teor de gordura na forma de: creme contendo $6,0 \mathrm{~g} / 100 \mathrm{~g}$, integral com $3,0 \mathrm{~g} / 100 \mathrm{~g}$ e desnatado menor que $2,9 \mathrm{~g} / 100 \mathrm{~g}$.

Segundo as normas da Organização Mundial da Saúde (FAO/WHO), no iogurte batido, a porcentagem de sólidos não gordurosos (SNG) deve estar na faixa de $8,5 \%$ a $10 \%$, o produto tradicional que é mais firme, deve ter $12 \%$ de sólidos não gordurosos. Os sólidos totais têm efeito marcante na firmeza do gel do iogurte. Em geral, quanto maior a porcentagem de sólidos, mais firme é o produto.

Segundo Klein e Richards (2003) na produção de iogurte costuma-se aumentar a quantidade de sólidos totais presentes no leite através da adição de leite em pó, concentrado proteico de soro e soro de leite, além de outros ingredientes. Já Penna et al. (1994) ao relatarem sobre a qualidade do iogurte e relatam as principais análises que devem ser realizadas: acidez titulável, pH, determinação da composição, shelf life, bem como a análise sensorial, consistência e textura. De acordo com a legislação para leites fermentados (BRASIL, 2000) descrito na Resolução ${ }^{\circ} 5$, de 13 de novembro de 2000, o iogurte deve apresentar de 0,6 a 1,5g de ácido láctico/100g. 
Já Hugunin (1999) para manter a aparência e a textura do iogurte é necessário um controle sobre o extrato seco, teor de proteínas, tipo de proteínas, bem como o tipo e a concentração de quaisquer espessantes ou estabilizantes adicionados ao meio.

Segundo relatos de Szcesniak (1963) a textura de um iogurte é focado pela sua coesividade, que está intrinsecamente relacionada as forças de ligações internas que formam um produto. A adesividade, voltada a força necessária para vencer as forças de atracão entre a superfície do alimento e outras interações presentes no alimento. Gomosidade, relacionada a energia requerida para mastigar um produto semi- sólido até o estado de degluti-lo.

Portanto, o principal enfoco deste estudo é relacionar as modificações decorrentes da adição de diferentes concentrações de sólidos totais, avaliando o perfil da textura e as características físicoquímicas do produto formado.

\section{Material e Métodos}

Para elaboração do produto iogurte sabor goiaba foi utilizado leite integral padronizado, polpa de goiaba comercial fornecido pela empresa Duas Rodas S.A. e cultura láctica (EZAL MYE 96 RPTEXEL, tradicional para iogurte, com a presença de cepas mistas de Lactobacillus delbrueckii subsp. bulgaricus e Streptococcus salivarius subsp thermophilus. Ingredientes como açúcar refinado, espessante/estabilizante Hx BLI S, leite em pó instantâneo desnatado e soro de leite em pó, corante natural de carmim, conservante sorbato de potássio, espessante/estabilizante, leite em pó desnatado, soro de Leite em pó.

Segundo o Decreto $\mathrm{n}^{\mathrm{o}}$ 2.244/97) é definido como iogurte "o produto obtido pela fermentação láctica via Lactobacillus delbrueckii ssp bulgaricus e Streptococcus thermophilus sobre o leite integral, desnatado ou padronizado". Além disso, seu acompanhamento pode ser integrado a outras fontes de bactérias que mantenham as principais características do produto acabado (BRASIL, 1997).

O procedimento descrito por Ferreira (1987) foi utilizado para elaboração do iogurte, com as diferentes concentrações para cada tratamento conforme formulação específica. Foram preparadas formulações com diferentes concentrações: utilizando como controle o espessante (ESP) e o padrão (P). E para as demais formulações foram identificas como: 5 e $10 \%$ de leite em pó (LP) 5 e $10 \%$ e 5 e $10 \%$ de soro de leite proteinado (SL) 5 e $10 \%$.

\section{Análises físico-químicas}


Para quantificação dos valores físico-químicas, proteína, lipídeos, cinzas, sólidos totais, sólidos solúveis/ $/{ }^{\circ}$ Brix, $\mathrm{pH}$ e acidez, análises foram realizadas e quantificadas conforme metodologia proposta pelo (IAL, 2004). Todas as análises físico-químicas foram realizadas em triplicada.

\section{Análise da textura}

Foram realizadas análises de textura, entre elas: adesividade, coesividade e gomosidade em iogurtes preparados conforme formulação já disponibilizada. Os iogurtes foram envasados e armazenados em potes plásticos cobertos por uma camada vedante de alumínio em temperatura de geladeira $\mathrm{a} \pm 8{ }^{\circ} \mathrm{C}$ até a realização do teste conforme descrito por (MACFIE, 1990). Foram realizadas 10 medidas de textura para cada tratamento. Todos os atributos voltados as análises de textura foram analisadas no equipamento TA-XT2i Stable Micro System. O procedimento para análise e interpretação dos resultados foram realizados conforme descrito a seguir: velocidade préteste: $2 \mathrm{~mm} / \mathrm{s}$; velocidade teste: $1 \mathrm{~mm} / \mathrm{s}$; velocidade pós-teste: $5 \mathrm{~mm} / \mathrm{s}$; distância de análise: $10 \mathrm{~mm}$; probe: cilindro de acrílico com $25 \mathrm{~mm}$ de diâmetro; força do trigger: $5 \mathrm{~g}$; volume da amostra: 60 +/$10 \mathrm{ml}$; temperatura: $9+/-2^{\circ} \mathrm{C}$ em condições reais de armazenamento.

\section{Resultados e discussão}

\section{Valores físico-químicos obtidos}

Ao analisar os teores obtidos para o perfil físico-químico com base na legislação brasileira voltada a leites fermentados, resolução $\mathrm{n}^{\mathrm{o}} 5$ de 13 de novembro de 2000, observa-se que os teores de lipídeos são teores de leite integral com 3,0g/100g conforme demonstrado na Tabela 1.

E ao analisar os teores de extrato seco total desengordurado, todos os tratamentos apresentaram-se dentro do limite definido pela Organização Mundial da Saúde (FAO/WHO), ao qual menciona valores superiores a $12 \%$ para iogurte com formulação tradicional. Segundo pesquisa apontada por Tamine e Robinson (1991) o teor de extrato seco total presente ao leite ultrapassar o teor de $25 \%$ haverá uma redução no teor de água disponível, interferindo no crescimento e desenvolvimento da cultura láctica sobre o meio. Foi observado durante o estudo, que a adição de sólidos totais sobre as formulações LP 5\% e SP 5\% bem como LP $10 \%$ e SP $10 \%$ apresentaram um aumento no ${ }^{\circ}$ Brix. Diante deste perfil foi observado que a amostra LP 5\% quando comparada a formulação LP $10 \%$ houve um aumento de $25 \%$, demonstrando consistência para os valores formulados. 
Tabela 1 - Valores físico-químicos das formulações de iogurte com diferentes concentrações de sólidos totais.

\begin{tabular}{lccccccc}
\hline \multicolumn{1}{c}{ Formulações } & EST (\%) & Cinzas & ${ }^{\mathbf{0}}$ Brix & Lipídeos & Proteína & pH & Acidez $^{\mathbf{0}} \mathbf{D}$ \\
\hline Padrão & $20,1 \pm 0,4$ & $0,46 \pm 0,1$ & $17 \pm 0,0$ & $4,0 \pm 0,1$ & $3,14 \pm 0,3$ & $4,8 \pm 0,1$ & $66,4 \pm 0,1$ \\
ESP & $22,9 \pm 0,2$ & $0,6 \pm 0,1$ & $17 \pm 0,0$ & $3,5 \pm 0,1$ & $3,58 \pm 0,3$ & $4,9 \pm 0,1$ & $65,6 \pm 0,1$ \\
LP 5\% & $21,7 \pm 0,8$ & $0,9 \pm 0,1$ & $18 \pm 0,0$ & $3,0 \pm 0,2$ & $3,42 \pm 0,4$ & $5,0 \pm 0,1$ & $66,2 \pm 0,1$ \\
LP 10\% & $29,9 \pm 0,4$ & $1,1 \pm 0,2$ & $24 \pm 0,0$ & $4,0 \pm 0,1$ & $5,89 \pm 0,4$ & $5,5 \pm 0,1$ & $67,0 \pm 0,1$ \\
SP 5\% & $25,0 \pm 0,1$ & $0,8 \pm 0,1$ & $22 \pm 0,0$ & $4,0 \pm 0,1$ & $3,76 \pm 0,5$ & $4,8 \pm 0,1$ & $66,5 \pm 0,1$ \\
SP 10\% & $27,0 \pm 0,2$ & $0,9 \pm 0,3$ & $24 \pm 0,0$ & $4,0 \pm 0,1$ & $4,05 \pm 0,5$ & $5,2 \pm 0,1$ & $67,1 \pm 0,1$ \\
\hline
\end{tabular}

Os teores físico-químicos das matérias minerais (cinzas) foram obtidos um aumento de $\underline{ \pm}$ $58 \%$ quando comparado ao valor inicial do padrão. E para o teor de proteína bruta os valores obtidos foram de 3,14 do padrão a 5,89 com a adição de sólidos totais, levando a um aumento de \pm 46,6\%. Mediante aos valores obtidos, todas as amostras de iogurtes analisadas e enriquecidas com teores de sólidos totais, apresentam-se dentro dos valores exigidos por lei mediante a Resolução $n^{\circ}$ 5, de 13 de novembro de 2000, que determina para iogurte quantidade mínima para o leite integral $\operatorname{com} 3,0 \mathrm{~g} / 100 \mathrm{~g}$.

Análise unidimensional na avaliação do perfil da textura

Após as análises os resultados realizados para os tratamentos voltados aos atributos da textura são demonstrados na Tabela 2.

Tabela 2 - Resultados dos atributos da textura realizados para cada formulação.

\begin{tabular}{lccc}
\hline \multicolumn{1}{c}{ Formulações } & Ades ividade (N.s) & Coesividade & Gomosidase \\
\hline Padrão & $0,007 \pm 0,0^{\mathrm{b}}$ & $0,83 \pm 0,1^{\mathrm{a}}$ & $0,10 \pm 0,0^{\mathrm{ac}}$ \\
ESP & $-0,03 \pm 0,0^{\mathrm{b}}$ & $0,83 \pm 0,0^{\mathrm{a}}$ & $0,12 \pm 0,0^{\mathrm{a}}$ \\
LP 5\% & $-0,26 \pm 0,0^{\mathrm{b}}$ & $0,63 \pm 0,0^{\mathrm{a}}$ & $0,11 \pm 0,0^{\mathrm{a}}$ \\
LP 10\% & $-0,11 \pm 0,0^{\mathrm{a}}$ & $0,60 \pm 0,0^{\mathrm{a}}$ & $0,10 \pm 0,0^{\mathrm{D}}$ \\
SP 5\% & $-0,05 \pm 0,0^{\mathrm{a}}$ & $0,63 \pm 0,0^{\mathrm{a}}$ & $0,09 \pm 0,0^{\mathrm{abc}}$ \\
SP 10\% & $1,62 \pm 0,1^{\mathrm{a}}$ & $0,80 \pm 0,2^{\mathrm{a}}$ & $0,05 \pm 0,0^{\mathrm{c}}$ \\
\hline
\end{tabular}

a, b,c -apresent am diferença à nível de $5 \%$ de significância.

$\mathrm{Na}$ adesividade (N.s) corresponde a força aplicada em Neuton por segundo.

Foi observado que o maior valor de adesividade foi encontrado para o LP 5\% e o menor foi para o SP $10 \%$ entre todos os tratamentos. Esses resultados indicam o poder que o sólido lácteo apresenta na interferência do atributo textura. Demonstrado para a formulação contendo o soro em pó SP que resultou em um produto pouco aderente em superfícies. E quando ingerido haverá percepção sensorial. Segundo Madrid et al. (1996) uma das principais inconformidades é a presença da elevada acidez, que afeta diretamente o atributo textura.

Os resultados para o atributo coesividade não demonstraram diferença estatística à nível de $5 \%$ de significância. Esse atributo permite avaliar a resistência do produto ao se dissolver durante a 
degustação do provador. A adição de soro em pó ou leite em pó não demonstrou diferença estatística à nível de 5\% de significância em relação ao iogurte adicionado ao espessante ESP e ao padrão $P$.

Para o atributo gomosidade, o tratamento ESP apresentou maior gomosidade seguido pelo tratamento LP 5\%, LP $10 \%$ e SP 5\%. O menor valor de gomosidade observado perante os resultados obtidos foi para o tratamento SP $10 \%$ o qual demonstrou difenças estatísticas para todos os tratamentos avaliados à nível de 5\% de significância. Este atributo avalia a característica gomosa que o produto apresenta ao ser degustado, ou seja, característica intrínseca de gomas ou agentes espessantes/estabilizantes adicionados aos produtos industrializados.

\title{
4 Considerações finais
}

As formulações propostas com a adição das diferentes composições de sólidos totais, melhoraram os atributos físico-químicos entre eles, proteínas e cinzas. O demais valores físicoquímicos obtidos estão dentro do padrão de identidade e qualidade para iogurtes, em especial para os teores de lipídeos. E ao comparar os valores texturais, observa-se uma elevada variação que indicou a influência dos sólidos totais nos atributos de textura voltados a adesividade, coesividade e gomosidade. Neste estudo P, ESP, LP $10 \%$ e SP 5\% mantiveram características aceitáveis para a adesividade em iogurtes. $\mathrm{O}$ atributo coesividade, apresentou valores considerados satisfatórios para esses tratamentos e produto final. E ao relacionarmos o atributo gomosidade, o mesmo caracterizouse como instável entre todos os tratamentos.

\begin{abstract}
The large consumption of dairy products such as yogurt, coming from origin animal sources, provide consumers of this food sources of minerals, amino acids, vitamins and other sources. And in Brazil, several research have provided development of yogurts with firmer consistency and attractive to the palate. Therefore, this study aimed to develop a fermented lacteal product with different concentrations of totais solids flavored guava the order to verify and evaluate the texture profile and modifications chemical-physical arising from influence concentrations of deferent and as resulting from the influence of different concentrations of total solids. The formulations were prepared using two control formulations, with a thickener $(T)$ and other standard $(S)$. And other formulations identified as: 5 and 10\% milk powder (MP) 5 and 10\% milk whey (MW). Among the chemical- physical study, all values obtained during the tests were in accordance with specific legislation for yogurt. And for the profile study the texture, the best results obtained for the attributes studied were for: S, T, MP $10 \%$ and $5 \% \mathrm{MW}$ characteristics that remained acceptable for the adhesiveness. The attribute cohesiveness values were considered satisfactory for these treatments and the final product. And to relate the gumminess attribute, it was characterized as unstable among all treatments.
\end{abstract}

Key-words: total solids, texture of attributes, development. 


\section{Referências}

BRASIL. Ministério da Agricultura e Abastecimento. Instrução Normativa n ${ }^{\mathbf{0} 5}$, de 13 de Novembro de 2000. Oficializa os "Padrões de Identidade e Qualidade de Leites Fermentados". Diário Oficial de 02 de janeiro de 2001.

BRASIL. Leis, decretos, etc. Decreto n ².224 de 4 de junho de 1997, Diário Oficial da União, Brasília, 5 jun. 1997 , Seç. I, p. 11555 (altera dispositivos do Dec. N 30.691 de 29 de março de 1952...).

BRASIL. Leis, decretos, etc. Recomendação n o 31 de 12 de junho de 1997 (Consulta Pública) Regulamento Técnico Mercosur de Identidade e Qualidade de Leites Fermentados, Diário Oficial da União, Brasília, 3 jul 1997, Seç. 1, p. 14064. (Internalizada no Brasil-DIPOA/MA-Resolução no 5 de 13 de novembro de 2000 republicada em 2/01/2001. Dis ponível em: http://www.agricultura.gov.br/das/dipoa/resolução leite fermentado.htm. Acesso em: 21 nov. 2010.

ÇON, A. H., ÇAKMAKCI, S., ÇA ĞLAR, A., GÖKALP, H.Y. Effets of different fruits and storage periods on microbiological qualities of fru it flavored yogurt produced in Turkey. Journal of Food Protection, v. 59, n. 4, p. 402406, 1996.

EARLY, R. Tecnologia de los Productos Lácteos. Zaragoza: Acribia, España, 2000.

FERREIRA, C. L. L. F. Produtos Lácteos Fermentados. Viçosa: Editora UFV, Minas Gerais, 1987.

FERREIRA, C. L. L. F. Produtos lácteos fermentados - aspectos bioquímicos e tecnológicos. Viçosa: Editora UFV, Minas Gerais, 2001.

FIGUEIREDO, M. G.; PORTO, E. Avaliação do impacto da qualidade da matéria-prima no processo industrial do iogurte natural. Revista Indústria de Laticínios, v. 7, n. 41, p. 76-80, 2002.

HUGUNIN, A. O uso de produtos de soro em iogurte e produtos lácteos fermentados. Re vista Leites e Deri vados, v. 9, n. 49, p. 22-23, 1999.

INSTITUTO ADOLFO LUTZ. Métodos físico-químicos para análise de alimentos. IV Ed ição. São Paulo, 2004.

KLEIN, K. L.; RICHARDS, N. S. P. S. Elaboração de iogurtes sabor morango utilizando leite em pó, soro de leite e whey protein concentrate (WPC 35\%) e uma bebida fermentada a base de extrato aquoso de soja (P30). In:Anais do XX Congresso Nacional de Lacticínios, Juiz de Fora/MG, v. 58, n. 333, p. 171-174, 2003.

LIMA, U. A.; AQUARONE, E; BORZANI, W. Fermentação lática. Ed itora Edgard Blucher Ltda, São Paulo, 1975.

MACFIE, H. J. H. Assessment of the sensory properties of food. Nutrition Reviews, v. 48, n. 2, p. 87-93, 1990. http://dx.doi.org/10.1111/j.1753-4887.1990.tb02910.x

MADRID, A.; CENZANO, I.; VICENTE, J. M. Manual de indústrias dos alimentos. São Paulo: Livraria Varela, 1996.

MIRANDA, K. E. S.; SANTOS, A. C. P.; JESUS, I. M.; SANTOS, K. B.; ALVES P.C. Desenvolvimento de metodologia para e laboração de iogurte de milho verde. Revista Leites e Derivados, v. 08, n. 45, p.51-53, 1999.

ORDÓÑEZ, J. A.; et al. Tecnol ogia de alimentos. A limentos de origem animal. Ed itora Artemed, v. 2, 2005.

PENNA, A. L. B.; OLIVEIRA, M. N.; BARUFFALDI, R. Avaliação da qualidade de iogurte. Revista Leite e Derivados, v. 03, n. 16, 1994.

ROCHA, C.; COBUCCI, R. M. A.; CRA VEIRO, D. A.; URZEDO, A. C. B.; OLIVERIA, E. A. G.; RODRIGUES, L. R.; LOPES, F. L. Análise sensorial de iogurte batido sabor pequi. Revista Food Indredientes, n. $23,2003$.

SÁ, F. V.; BARBOSA, M. O leite e os seus produtos. Portugal: Editora Clássica, 5 ed, 1990.

SILVA, P. H. F.; PEREIRA, D. B. C.; OLIVEIRA, L. L.; COSTA JR, L. C. G. Físico-química do leite e derivados: métodos analíticos. Juiz de Fora/MG: Oficina de Impressão Gráfica e Editora LTDA. 1997.

SOROA, J. M. Indústrias Lácteas. Bib lioteca Técnica Litexa, 5 ed., 1980. 
SZCESNIAK, A. S. Classification of te xtural characteristics. Jornal Food Science., v. 28, n.1, 1963.

TAMINE, A. Y.; ROBINSON, R. K. Yogurt: ciência y tecnologia. Zaragoza: Acribia, Espanha, 1991.

Submetido em 27 jan 2011, Aceito para publicação em 22 mai. 2012. 